a few months of comfort rather than years of useful work. If he bear this in mind he will realise that the expectation of life of the patient is directly proportionate to the speed and simplicity of his operation.

\title{
THE DOME
}

"Wisdom is the principal thing; therefore get wisdom: and with all thy getting get understanding."-Proverbs iv. 7 .

\section{ANAESTHESIA IN GALL BLADDER SURGERY}

\author{
By FRANKIS EVANS, M.B., B.S., D.A. \\ (Anaesthetist, St. Bartholomew's Hospital; St. Mark's Hospital, etc.)
}

Surgery of the gall bladder necessitates the closest co-operation between the surgeon and the anaesthetist. The former has a delicate operation to perform, and is often working in the depths of a fat abdomen. The anaesthetist has to deal with a patient who is only too frequently fat and portly and difficult to anaesthetise. Even as the accompanist can make or mar the vocalist's performance, so can a bad anaesthetic render the surgeon's task well nigh impossible. The anaesthetist has a threefold duty, firstly to the patient, secondly to the surgeon, and lastly to himself. The patient should be anaesthetised with as little disturbance and unpleasantness as possible, and by that method which interferes least with the physiological processes of the body. The respiration should resemble that of sleep, so that the body does as little work as possible, and the surgeon's task is aided by the diminished movement. The surgeon needs absolute muscular relaxation of the abdomen as well as quiet respiration. Lord Moynihan's dictum, "Every pull means a pain," is very true, and if relaxation is complete no retractors need be used, and the time taken over the operation is materially reduced. The longer a patient is on the operating table the more likely is he to suffer with post-operative complications. The anaesthetist's duty to himself is to know his own limitations, and not to attempt that technique with which he is not really familiar, for this leads to failure and even to disaster. Ether may be undesirable and unpleasant post-operatively from all points of view, but it is better to be sick and to cough than to be the subject of an inquest! A sane and balanced outlook is essential.

The choice of anaesthetic and the method of administration is dictated by the condition of the patient, the time the operation will take and one's own personal prejudice. Inhalation anaesthesia held pride of place for many years, and both chloroform and ether have had their protagonists. The necessary muscular relaxation can be obtained in other ways, however, and the modern anaesthetist has a choice of several methods. Intravenous anaesthesia, spinal analgesia, and regional analgesia can each be used to give relaxation, but care must be exercised in employing any one of these methods. The indications and contra-indications for their use are discussed below. The patient's condition, both mental and physical, must be carefully considered. The frightened patient is more difficult to anaesthetise than the placid one, and requires more anaesthetic. The "Falstaffs" are also difficult, largely owing to their build. On the other hand these portly patients who habitually do themselves well seldom suffer with post-anaesthetic vomiting! The anaesthetist should know the condition of the patient's cardiovascular system (myocardium, blood pressure, arterio-sclerosis, etc.). The liver and renal function, too, should be known, for the blood urea is a very good guide of a patient's general condition. It is obvious that a fat, jaundiced patient with a flabby heart and poor excretory system will need more care than will a young, thin, wiry patient. Not only has the anaesthetist several separate methods of approach, but he may use a combination of methods.

Inhalation anaesthesia for gall bladder surgery calls for third plane anaesthesia, that is to say, full muscular relaxation. The surgeon is completely in the hands of his anaesthetist when inhalation anaesthesia alone is used, for if the patient be not sufficiently relaxed, the operation may be well nigh impossible. Chloroform alone can be used, but is not recommended, and 
is absolutely contra-indicated in the jaundiced patient, or where liver damage is suspected. On the other hand, chloroform may be used in conjunction with ether in a Boyle's gas oxygen machine, and very smooth anaesthesia obtained. The control lever of the chloroform must not be advanced further than the halfway position. For many years the writer used this technique of gas-oxygen-chloroform-ether by insufflation through a small intra-tracheal catheter, with satisfactory results. Certain precautions should be taken pre-operatively if chloroform is to be used. It is essential that the patient's liver be well charged with sugar, and to this end glucose or cane sugar should be given by mouth up to within three hours of operation. Trichlorethylene (trilene) may be used instead of chloroform, and in exactly the same way. (1) Ether has been used for many years as an anaesthetic both by the open and partly closed method. Apart from its irritant action upon the lung, and its nauseating post-operative taste, there is nothing more to say against it, except that its sphere of usefulness has much diminished since the advent of cyclopropane.

Cyclopropane is an excellent anaesthetic gas for abdominal surgery if used carefully and properly. Complete relaxation can be obtained, and the respiratory movement is minimal. In fact controlled respiration is usually necessary to obtain full relaxation. This gas is used in a closed circuit apparatus in which provision is made for the absorption of the carbon dioxide from the patient's breath by means of soda lime. Cardiac irregularity may occur as the anaesthesia progresses but the pulse becomes regular again as deep anaesthesia is rea-hed. (2) This temporary irregularity is said to be of no significance, on the other hand, bradycardia is a danger signal. (3) The writer feels that it is wiser to add a little ether if full relaxation is not obtained easily with cyclopropane. $\mathrm{He}$ also feels that the anaesthetist should have full control of the air passages when using this gas, therefore, the use of an endotracheal catheter is recommended. Cyclopropane is non-irritant, and therefore suits the bronchitic patient. On the other hand, there is some degree of nausea and vomiting post-operatively, though this is usually of a much milder degree than is seen in ether anaesthesia. It is the writer's custom to induce anaesthesia with a small dose of intravenous pentothal before using cylcopropane. As a rise of blood pressure is sometimes seen in the early stages of cyclopropane anaesthesia, it is not recommended in those patients who have a raised blood pressure and arterio-sclerosis. Cyclopropane does not damage the liver so that it is not contra-indicated in the jaundiced patient. (4)

Intravenous anaesthesia is used by some anaesthetists for upper abdominal work. Pentothal is the usual drug, and a mild degree of premedication with omnopon grs. $\mathrm{I} / 3$, scopolamine grs. I/I50 is advisable. This method calls for the very careful selection of patients, and is not recommended as the sole anaesthetic in tough and hefty patients, as they would require too much pentothal in too short a time; consequently, the body might be called upon to detoxicate more pentothal in a given time than it could adequately deal with. The writer prefers pentothal as an adjuvant rather than as the main anaesthetic. Much has been said regarding the short acting barbiturates being contra-indicated in jaundiced patients, and where severe liver damage is present. The writer has used it for induction purposes in three patients who were found at operation to have advancel cirrhosis of the liver. None of these patients were any the worse, in fact they seemed to burn away the pentothal more rapidly than the normal patient. Since then the writer has used pentothal in cautious doses $(5 \mathrm{cc}$. or $6 \mathrm{cc}$. of 5 per cent solution) as an induction even in jaundiced patients, with no ill effects.

Spinal anaesthesia fell into disrepute among some surgeons for upper abdominal operations owing to the big fall of blood pressure entailed. It is advisable to have anaesthesia up to $\mathrm{T}_{5}$ when operating upon the gall bladder. The writer perfers heavy nupercaine ( $\mathrm{I}$ in 200 in 6 per cent glucose), and the dose employed is $I .8$ c.c. injected intrathecally through the second or third interspace. The patient is placed in a $5^{\circ}$ Trendelenberg position for some five minutes after the injection. The technique has been described elsewhere as also has that for light percaine and novocain crystals. (5) The blood pressure is maintained by the use of an intravenous drip of I in 250,000 adrenalin (2 c.c. of I in I,000 adrenalin is added to every 500 c.c. normal saline). The speed of drip varies, but is something like 50-6o per minute. Some 200 to 250 c.c. of diluted adrenalin is used per hour. (6) It is important that the drip be continued postoperatively until the patient's own blood pressure mechanism is working again. Adrenalin is so rapidly destroyed in the body that the method is quite safe. If the drip be stopped the blood pressure falls almost instantly. This technique, too, has been described more fully elsewhere. Spinal analgesia does not remove the likelihood of chest complications, but is a means of getting 
relaxation without the use of ether. The writer prefers that all patients who have had a spinal anaesthetic should be asleep while the operation is in progress. It is kinder to the patient, and allows for any little adjustment in the balance of anaesthesia which may be required, e.g. the wearing off of the spinal analgesia before the completion of the operation.

Regional analgesia may be used according to the method of James, (7) who uses a posterior intercostal block from $T_{5}$ to $T_{12}$ inclusive, together with a posterior splanchnic block. The technique is not difficult, and excellent anaesthesia is obtained. The writer uses a combination of posterior intercostal block, with pentothal and gas oxygen, omitting the splanchnic block. The abdominal field (8) block may be used, in combination with pentothal and gas-oxygen, novocain 0.5 per cent (with $\mathrm{I}$ cc. of $\mathrm{I}$ in $\mathrm{I}, 000$ adrenalin added to every 250 c.c. of novocain solution) is used for the field block, which is easily performed, and need take no more than five minutes to complete. The needle is inserted just below the xiphisternum and runs deep between the internal oblique and transversalis one inch below and parallel to the costal arch. A long needle is used for this, and both sides may be infiltrated through the same skin puncture hole. The rectus muscle is infiltrated through one skin puncture on either side at a spot one inch or so above the umbilicus and one inch lateral to the outer border of the rectus muscle. The rectus sheath is punctured at several points by fanwise injections through this one skin puncture. The injection should be aimed at the under surface of the rectus muscle. A final puncture may be made, if desired, from the outer border of the costal arch downwards towards the iliac crest. Having performed the deep injections, a superficial infiltration of the subcutaneous tissues is made in the line of the incision. Relaxation lasts as a rule for some 45 minutes when novocaine is used.

The combination of methods has much to recommend it provided that a sane and balanced outlook is preserved. The protagonists of balanced anaesthesia maintain that the body can deal with a little of several drugs more easily than with a lot of one. Be this as it may, the writer feels that he personally would prefer oblivion while a surgeon (however delicate of touch) was manipulating his gall bladder or common bile duct. Thus, if a regional or spinal block is chosen for obtaining the necessary relaxation, the writer invariably induces sleep with a little pentothal intravenously, and maintains oblivion with a straight gas-oxygen.

Premedication. The writer prefers a mild sedative to be given the night before operation (medinal grs. $7 \frac{1}{2}$ ), and omnopon grs. I/3, scopolamine grs. I/I50 hypodermically one hour before operation. Atropin is never used as the drying-up effect of the two other drugs is quite adequate. However, if cyclopropane is to be used, I/roo grs. atropin is added in order to diminish the likelihood of cardiac irregularity. The above premedication helps in the sedation of the patient and diminishes the amount of pentothal required. At the same time, it tends to quiet respiration, thus aiding the urgeon. If no pentothal is to be used and no ether is intended, then the omnopon is increased to grs. 2/3. This enables the anaesthetist to maintain light anaesthesia with gas-oxygen alone, provided that relaxation is to be obtained with regional or spinal methods.

Post-operative treatment.-After cholecystectomy respiration is painful, and therefore the patient tends to breathe as lightly as possible. Pulmonary collapse is to be avoided if possible, and one way of preventing it is to make the patient breathe 5 per cent carbon di-oxide in oxygen at 2 hourly intervals (when awake) for some two or three minutes at a time. This achieves deep breathing, which the patient is quite unable to perform voluntarily. The "chesty" patient needs help, and the writer recalls the practice of one experienced sister, who always persuaded the house surgeon to prescribe a good expectorant cough mixture (Haustus senegae ammon. with fot. iod. grs. 5 (St. Bart's)). This loosens the phlegm and enables the patient to cough less painfully. Morphia is an essential in the post-operative treatment. It relieves the pain, and thus helps the patient to breathe more deeply.

Vomiting can be minimised by persuading the patient to take nothing by mouth, not even fluids, for some four or five hours following the return to consciousness.

\section{Conclusion}

It may be said that it is not so much the actual anaesthetic used, but the way it is given which counts most. The anaesthetist's aim should be to give adequate relaxation coupled with quiet respiration. This is to be obtained with the least disturbance to the patient, both mentally and physically. There are so many ways of obtaining the necessary relaxation that 
no hard and fast rules can be laid down as to which method is the one of choice. Personal prejudice enters into the decision to a very large degree, and the wise anaesthetist will not abandon a method in which he is expert for one in which he is not proficient. For in that direction may well be disaster.

\section{REFERENCES}

I. HEWER, C. L., Recent Advances in Anaesthesia and Analgesia.

2. THIENES, C. H. (et al.), A naesthesiology, I94I, November, p. $6 \mathrm{rr}$.

3. WATERS, R. M., B.M.J., r 936 , November 21 , p. ror 5 .

4. HEWER, C. L., Recent Advances in Anaesthesia and Analgesia.

5. EVANS, FRANKIS, "Spinal Anaesthesia with heavy percaine," Proc. Roy. Soc. Med. (An Sect.), August I94I, Vol. XXXIV,

EVANS, FRANKIS, “Present position of Spinal Analgesia,” Medical Press and Circular, December 16, 1942, pp. 399 et seq.

6. EVANS, FRANKIS, Lancet, January I, 1944, p. 15.

7. JAMES, NORMAN, Regional A nalgesia for Intra-abdominal Surgery.

8. LABAT, G., Regional Anaesthesia, p. 363.

\section{RUTHIN CASTLE, NORTH WALES}

A Clinic for the diagnosis and treatment of Internal Diseases (except Mental or Infectious Diseases). The Clinic is provided with a staff of doctors, technicians and nurses.

The surroundings are beautiful. The climate is mild. There is central heating throughout. The annual rainfall is $\mathbf{3 0 . 5}$ inches, that is, less than the average for England.

The inclusive fees are from 15 guineas a week, according to the room occupied; rooms with bathroom are from 21 guineas. An examination and consultation fee of 15 guineas is charged on the first visit only. doctor.

SPECIAL FEES FOR INVESTIGATION ONLY - 30 GUINEAS, including stay up to 10 days and report to

For particulars apply to THE SECRETARY, Ruthin Castle, North Wales.

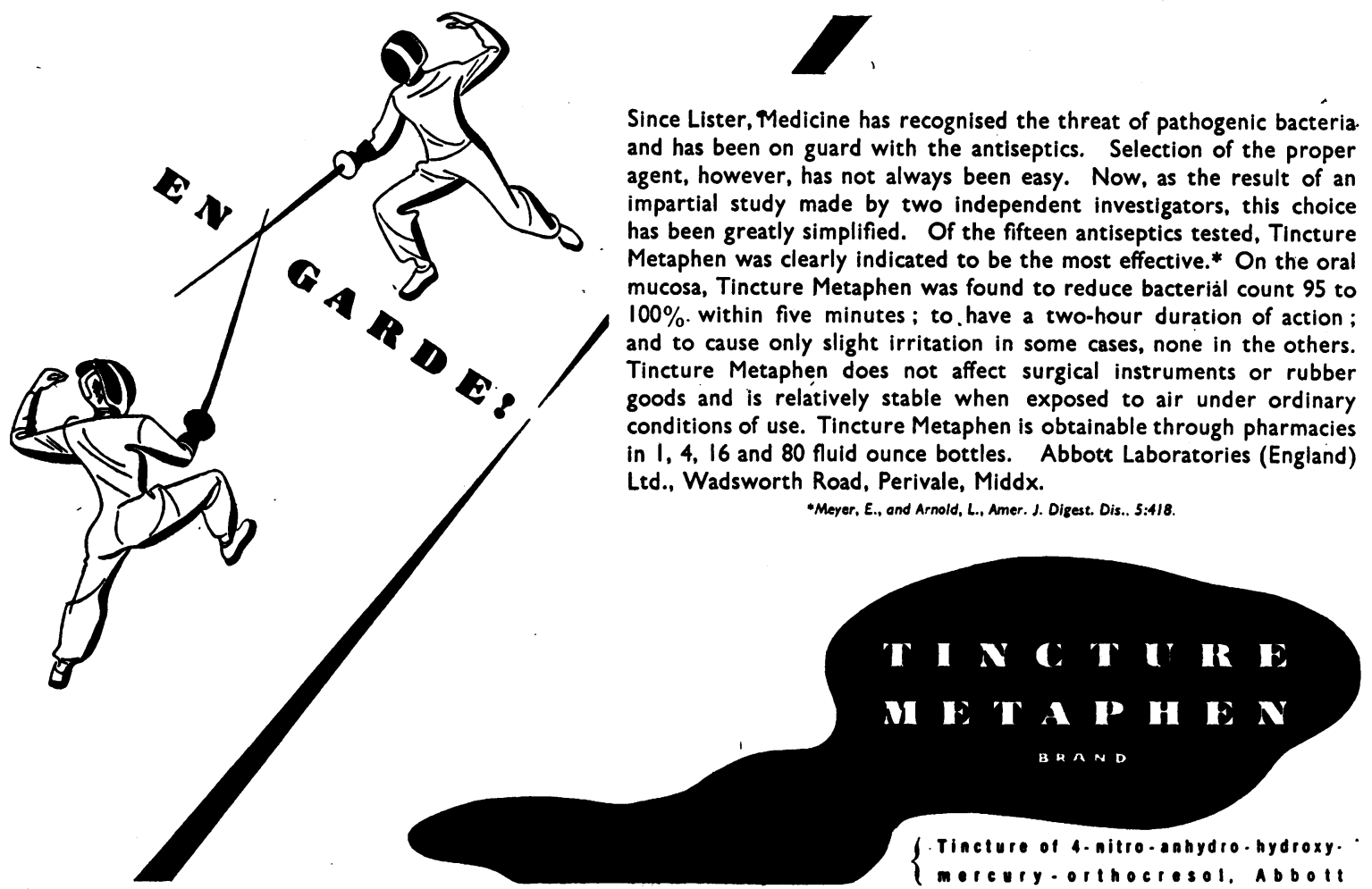

